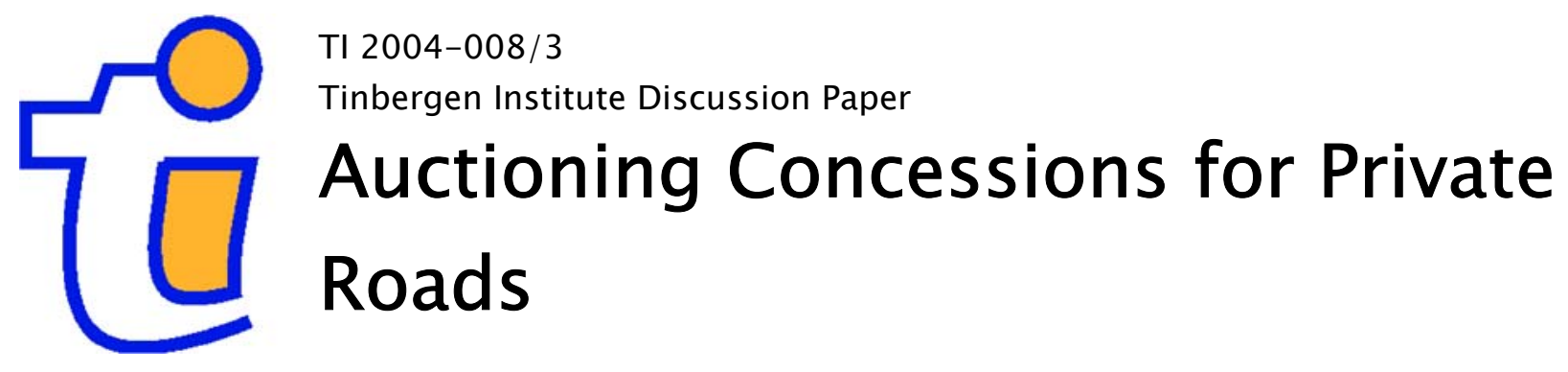

Barry Ubbels

Erik Verhoef*

Department of Spatial Economics, Faculty of Economics and Business Administration, Vrije Universiteit Amsterdam.

* Tinbergen Institute. 


\section{Tinbergen Institute}

The Tinbergen Institute is the institute for economic research of the Erasmus Universiteit Rotterdam, Universiteit van Amsterdam, and Vrije Universiteit Amsterdam.

Tinbergen Institute Amsterdam

Roetersstraat 31

1018 WB Amsterdam

The Netherlands

Tel.: $\quad+31(0) 205513500$

Fax: $\quad+31(0) 205513555$

Tinbergen Institute Rotterdam

Burg. Oudlaan 50

3062 PA Rotterdam

The Netherlands

Tel.: $\quad+31(0) 104088900$

Fax: $\quad+31(0) 104089031$

Please send questions and/or remarks of nonscientific nature to driessen@tinbergen.nl.

Most TI discussion papers can be downloaded at http://www.tinbergen.nl. 


\title{
Auctioning concessions for private roads
}

\author{
Barry Ubbels \\ Erik Verhoef \\ Department of Spatial Economics \\ Free University Amsterdam
}

\begin{abstract}
Private toll roads are now seriously considered as an alternative to public (free-access) road infrastructure. Nevertheless, complete private provision without governmental control is only rarely considered. A main consideration against private roads would be that operators would be primarily interested in maximizing profits, which - given the market power they will have - will typically not lead to welfare maximizing tolls and capacities. An important question is whether these discrepancies can be mitigated by a proper design of auctions for concessions of private roads. This paper therefore analyses capacity choice and toll setting by private investors in a competitive bidding framework organised by the government. We develop a two-link network simulation model with an untolled alternative to determine relative efficiency effects, and analyse rules for the government to organise the bidding process such that a more desired (welfare optimal) outcome is achieved. Our results show that, depending on the design of the auction, its outcomes may vary strongly, and may approach the maximum possible (second-best) welfare gains.
\end{abstract}

\section{Introduction}

Transportation is a sector in which governments around the world are heavily involved. This may take several forms, ranging from small regulatory rules to full ownership and operation of particular services. Transportation infrastructure, such as highways, ports and airports, absorbs a large share of public sector capital investments in most countries (Gomez - Ibanez and Meyer, 1993), and price setting has often been determined primarily by policy objectives rather than the market.

Things are changing however, and private involvement in the provision of infrastructure is increasing nowadays, following deregulation and privatization in the US and in the UK during the past decades. In fact, private supply of infrastructure is not a new idea, as the early development of railways, canals, ports and inter-urban highways in many parts of the world was market led by private sector entrepreneurs. The return of interest in private involvement can mainly be explained by the growing concern over public budgetary deficits, and the perceived inability of public bodies to manage complex infrastructure efficiently.

In this paper we focus on the involvement of private firms in the provision of road infrastructure. We are in particular concerned with the dilemma caused by the fact that private operators through potentially bringing efficiency improvements - will be primarily (or exclusively) concerned with profit maximization. Specifically, we will consider the question of whether the associated welfare losses can be mitigated by optimizing the design of auctions for the right to privately build and operate a certain road. We present a small two link simulation model to 
analyze the effects of various types of private bids for the right to build and operate a new road parallel to an existing road.

The paper starts with some basic (pricing) issues related to the involvement of private parties in road infrastructure provision. Section 3 introduces the model, and presents some simulation results when private firms may bid on the construction and operation of a road in an auction. Section 4 concludes.

\section{Investment and pricing of road infrastructure}

Investments in transport infrastructure are usually done by the public sector, and private involvement has so far been limited. The private sector usually seeks for commercial profit that can be gained either as income from investments interest, or as value capture through an improvement in the transport system (ITS Leeds and partners, 1999). Despite higher cost of capital raised from commercial sources and the need to cover the risks and gaining commercial profit, it may be that the overall cost for the community will be lower with private financing than if taxation funds are used. This can then be explained from the efficiency improvements in management due to the profit motive of private enterprises. Moreover, government funds are often raised using distortive taxes, which may further increase the social costs of public investments (this argument looses relevance when comparing priced public and private roads). Private management may lead to increased innovative ideas in the project, or to more rapid decision-making. Private financing may also minimise the debt burden or financial guarantees on the finances of the government and increase the financial resources that might be available for the projects.

Despite these potential benefits to the public sector, it may be difficult to interest private investors in financing roads due to considerable risks and uncertainties making infrastructure not a very attractive investment. One of them is the high fixed costs and the long construction and planning periods, which cause the need for large sums of capital in the beginning, while the payback period is very large (see Rienstra and Nijkamp, 1997, on the various risks and uncertainties for private investors).

The downside of private road provision is that governments often fear the pricing strategies of the private firm. It may be expected that, when allowed to build and operate infrastructure, firms will not price efficiently and will set charges higher than marginal social costs (e.g. Verhoef et al., 1996).

The relationship between the total costs of the infrastructure manager, and the revenues collected by tolls, when the charges were set equal to marginal social costs, will depend upon the underlying cost conditions in the supply of infrastructure conditions. If the long run average costs (when all inputs are variable) are falling over the relevant range of output (increasing returns to scale), marginal cost based charges will tend, on average, to yield less than the full ongoing costs of the infrastructure manager. The reverse will hold in the case of decreasing returns to scale; then profits can be made. Constant long-run average costs will enable full cost recovery (Small, 1998 and Mohring and Harwitz, 1962). Studies of cost conditions, and the evidence of the revenues produced when marginal cost reflective charges have been applied in practice, suggest that the extent of scale economies varies between the different types of transport infrastructure (NERA et al., 1998). Road infrastructure tends to show returns to scale that are approximately constant (e.g. Small, Winston and Evans, 1989). This pattern of project returns will encourage a highly conservative approach by the private sector to provide 
infrastructure against marginal cost based prices, since the resulting profits would be small or negative. It is therefore not surprising that most projects of interest to private investors have been those which are discrete, clearly bounded and largely self-contained with no close-competitor. Indeed, most common privately financed schemes have been bridges and tunnels (Vickerman, 2002). Nevertheless, the introduction of congestion charging is of great importance to the financial viability of private involvement as it can provide a stable revenue source which could cover large parts of the costs ${ }^{1}$.

For this reason, governments may wish to consider exercising some control over the process. The natural monopoly argument has been and still is the underlying rationale for public involvement in infrastructure provision since the nineteenth century (see Vickerman, 2002). Most toll bridges do face price controls for instance. Pure private financing in which the private party carries all costs, runs all risks, and receives all revenues from user charges, is therefore only seldom the case.

Financial regulation can take several forms, including a maximum toll rate indexed to inflation (as in France (Fisher and Babbar, 1996)), a return on investment ceiling, and traffic or revenue guarantees (e.g. shadow tolling where the government guarantees a certain toll depending on the traffic which takes away a great deal of commercial risks). An indexed maximum toll rate is the most common form of regulation, mainly due to its practical advantages (Fisher and Babbar, 1996). Return on investment regulation with no toll rate ceiling is more flexible in allowing toll rate adjustments to optimize revenues. California, for instance, selected an innovative one-time contractual approach, setting the ceiling for the rates of return allowed over the life of the project in each franchise agreement.

The specification of the design of the road may range from virtually no public involvement to public sector responsibility for preliminary design (including capacity, location and number of interchanges and crossings, materials used etc.). Although little information is available about current practice, it is often the public sector that selects project proposals meeting their predefined conditions. At the same time, a lower level of public responsibility for design allows the private sector to bring in innovative solutions and better match market demands. Bidders for the SR 91 road in California, for instance, had full responsibility for all project design subject to governmental approval. The contract was fully negotiated only after a concessionaire was selected. The basis for comparing bids and selecting the concessionaire was therefore somewhat subjective, since the government had to compare different designs of the project. However, this process allowed the private sector to propose innovative projects and designs and negotiate risksharing terms (Fisher and Babbar, 1996).

It can be concluded that governments want to keep some form of control when private firms are involved in road construction and operation. Governments have various options to control private firms of which many focus on toll regulation when the road is already constructed. It may well be the case that governments want to leave both construction and operation to the private sector, but still keep control over design of the road and toll levels. This was the case in California (SR 91) when a private firm was allowed to build a new lane parallel to an existing road. Instead of applying separate types of regulation, governments may also decide to organize

\footnotetext{
${ }^{1}$ In addition to the commercial profit that is dependent on the investment time, interest rates and risk management, participation in financing of the transport infrastructure can bring value capture benefits to the investor. This can take the form of increase in property values, attraction of customers, facilitation of employee's travel to work and provision of cheaper and more reliable transport opportunities.
} 
an auction. Private firms are then invited to do a bid and obtain the right to construct and operate a road. This bid would include a specification of the design of the road and the toll level that will be levied during operation. In a setting of open bidding certain evaluation criteria may be set by the government, determining the quality of a project proposal. It may set specific rules to obtain an offer that meets their objectives. In the following section we will analyze the effects of an auction, and in particular the consequences of setting different rules to evaluate the bids of private firms.

\section{A modelling framework to select a private road bid}

From the viewpoint of society, it is important to assess the welfare implications of the construction of a new road. Certain toll levels and capacities may lead to profits but need not maximize welfare, or vice-versa it is important to know whether an optimally designed road will generate welfare gains but without being profitable (and hence be unattractive to private firms). This is important information both to governments and the private provider of infrastructure. We develop a model that allows us to study these questions in a relatively simple setting. We are particularly interested in the question of how auctions for concessions to build and operate a private road can be used to optimize two decision variables of interest: the road's capacity and the toll that will be charged.

We will use a simulation model to investigate the consequences of various types of roads (differing in capacity and toll) in terms of welfare and profit, and to find suitable 'indicators' for selecting the winning bid, that governments could use in auctions. For instance, an auction with the rule that the bid with the maximum capacity (which is possibly a relevant objective for an authority) will get the right to build and operate, may not necessarily lead to the optimum in terms of welfare (and hence be an inferior indicator). The consequences of various auction rules will be investigated by using a simple two-road network. The model will be explained in greater detail after we have discussed previous studies that use a similar setting.

\subsection{Previous studies}

Analytical studies have paid attention to the welfare consequences of different ownership (and thus pricing) regimes. Several analytical studies of private toll roads can be found in literature. Most of them consider a simple road network with one origin and one destination connected by one or more parallel routes (Edelson, 1991; and Mills, 1981). Many employ static models, in which drivers' choice is limited to route and travel demand, possibly with flat tolls (time independent). Recognizing that institutional constraints may prevent implementation of optimal tolls, more recent research has focused on the properties of second-best tolls, which are computed subject to given constraints. A common constraint encountered in practical situations is that tolls are only implemented on single lanes or roads, with travel on alternative routes being unpriced. An example is the SR 91 road in California (Liu and McDonald, 1998). Imposition of 'quasi first-best pricing' on the toll road (simply ignoring spill overs to the unpriced parallel road) is then not welfare maximising (Lévy-Lambert, 1968; Marchand, 1968). One analysis of different ownership regimes is in Verhoef et al. (1996), who considered a network with one origin and one destination connected by two parallel routes. The authors consider two private ownership regimes; one in which one of the routes is private and the other is free access, and a second situation in which a private monopoly controls both routes. It is shown that revenue maximising tolling on two routes may actually lead to a more efficient usage of road space than 
does optimal one route tolling. Hence, it may be more efficient to have a monopolist controlling the entire network, rather than just a part of it. Verhoef and Small (2003) obtained a similar result in a comparable set up which, however, allows for the heterogeneity with respect to value of time.

De Palma and Lindsey (2000) focused on allocative efficiency of private toll roads vis a vis free access and public toll road pricing on a similar network, but allowing for dynamics of peak congestion. This study suggests that two competing private roads can yield most of the potential efficiency gains from first-best pricing if neither road has a dominant fraction of total capacity. They look at two parallel routes between one origin and destination that can differ in capacity and free flow travel time. A single private road competing with a free-access road tends to be most efficient if the two roads have approximately equal capacities and if the private road does not suffer a significant travel time disadvantage.

Yang and Meng (2000) look at the selection of the capacity and toll charge of a new road (in a build-operate-transfer (BOT) framework) and the evaluation of the relevant benefits to the private investor, the road users and the whole society. A profit maximising private firm will consider the trade-off among traffic demand, toll charge and road capacity. Toll setting and capacity choice by private organisations will have important consequences in terms of efficiency, which may call for government intervention. The Yang and Meng study investigated private sector profit and total social welfare gain generated from a proposed BOT project under a wide range of capacity-toll combinations and employing a general road network. They show how, and under what circumstances, a highway project is profitable, and how it may benefit the road users. Tsai and Chu (2003) study regulation alternatives for governments on private highway investment under a BOT scheme set up to protect both consumers and firms. The impact of various circumstances (such as a minimum flow constraint) on traffic demand, as well as users' cost, profit levels, and welfare are explored. They find that a BOT project with regulation performs between the cases of maximizing welfare and that of maximum profit.

Our analysis is possibly closest to that by Tsai and Chu (2003). However, they focus on two types of regulation for one private firm that will construct the road. We focus here on the auctioning of concessions to privately operate the road, and consider various criteria ('indicators') that a government may use to realize more satisfying bids from interested firms.

\subsection{Model formulation}

In our model, we study the relative efficiency of a new route, parallel to an existing untolled alternative, that is to be operated and constructed by a private firm. The case of a new road without an existing substitute is a special case of our model, that is reached as the existing road's capacity is set equal to zero. We assume that the existing (public) road will remain untolled. It is well-known from the prior literature that an unrestricted monopolist would prefer to set tolls and capacity at profit maximizing rather than welfare maximizing values. We consider the question of how such behavior can be affected by using particular types of auctions for the right to operate the private road. Clearly, if the government would have perfect knowledge of prevailing demand and cost conditions, it would be simple to design such an auction: the firm that promises to set toll and capacities equal to the socially optimal (second-best) levels would win the concession. Auctions become relevant only if the government is uncertain about what is optimal, while potential suppliers have more information. We assume that this is the case. Specifically, we assume that suppliers have perfect knowledge of the market conditions, and that the government 
only knows the (single) value of time of the road's potential users ${ }^{2}$. Otherwise, we make assumptions that will prevent any other distortions from affecting the (relative) efficiency of the auctions we consider. First, we will assume that there is competitive bidding: there is no tacit collusion between bidders, they do not have market power in the bidding process, and bids will be such that the winning firm will make zero profits. Secondly, we assume that the potential bidders are identical. Under these unrealistic, idealized conditions we can focus on the performance of different indicators that the government could use in setting up auctions for roads. And thirdly, we assume that the firms make truthful bids, that is: bids that they will indeed bring into practice once given the concession. This means that we implicitly assume that there is a credible and effective penalty on deviating from the bid made. The complications arising when these assumptions are not fulfilled are certainly interesting, but considered as material for future work. These include the existence of differences between potential firms, the existence of collusion during the auction, other imperfections in the auction when the number of bidders becomes smaller, the existence of uncertainty also for the potential bidders, etc. Finally, we assume that the government has the objective of maximizing social surplus defined as total (Marshallian) benefits minus total user costs (including time costs), minus the capacity costs. The objective of the private road operators would normally be to maximize profits, defined as total toll revenues minus capacity costs. However, when an auction is in place, the firm's objective will become to maximize (or minimize) the indicator specified by the regulator, under the constraint that the profits from operation be non-negative. For all auctions we consider, this constraint will be binding. The idea is thus that a firm that would not maximize (or minimize) the indicator would be certain not to win the auction.

The challenge faced by the government is then as follows: can an auction be designed that leads the bidding private firms to propose a capacity and toll that are close to the second-best optimal value? Specifically, which 'indicator' (the target variable that bidders should maximize or minimize and that thus will be used to select the winning bid) will achieve this objective as closely as possible?

Our network model builds on the one used by Verhoef and others (1996). Our analysis however, includes capacity and capacity costs, which enables us to compare different combinations of toll and capacity proposed by the bidders, leading to various profit and welfare levels. But the general setting is the same: a simple network with two competing (possibly) congested roads. One route (the existing one) remains free of toll (route $U$ ) and another route will be built and tolled by the concession winning private firm (route $\mathrm{T}$ ).

Car drivers regard the two alternatives as perfect substitutes We therefore consider one single demand function $D(N)$, where $N$ denotes the total number of road users on both routes (naturally $N=N_{T}+N_{U}$ ), and two average user cost (including time costs) functions $C_{T}\left(N_{T}, \operatorname{cap}_{T}\right)$ and $C_{U}$ $\left(N_{U}, \operatorname{cap}_{U}\right)$. In line with Wardrop's first principle (Wardrop, 1952), at any equilibrium the average cost on route $U$ should then be equal to the average cost on route $T$ plus the one-route fee $t_{T}$ : otherwise people would shift from one route to the other. Furthermore, both average costs should be equal to marginal benefits $\left(D(N)=D\left(N_{T}+N_{U}\right)\right)$. We assume that the demand is linear:

\footnotetext{
${ }^{2}$ This assumption is made to secure that both the government and all bidders can communicate in terms of average user cost without having to worry about different parties having a different view on the relation between equilibrium travel times and implied average user costs. This is relevant for some of the auctions we consider below, in which the indicator includes the generalized price (average travel costs plus toll) on route $\mathrm{T}$.
} 


$$
D=d-a *\left(N_{T}+N_{U}\right)
$$

Next, for both routes $i$, the average social cost $\left(c_{i}\right)$ consists of a free-flow cost component $k_{i}$ and a congestion cost component, which is assumed to be proportional to total road usage $\left(N_{i}\right)$ with a factor $b_{i}$, being a constant term divided by the capacity of the road;

$$
\begin{array}{ll}
c_{i}=k_{i}+b_{i} * N_{i} ; & i=T, U . \\
b_{i}=\beta / \text { cap }_{i} ; & i=T, U .
\end{array}
$$

The generalized price, for both roads, can then be defined as the sum of $c_{i}$ and the toll (if any);

$$
p_{i}=c_{i}+t_{i} ; \quad i=T, U
$$

Profits $\left(\pi_{T}\right)$ for the private operator are defined as the difference between revenues from the tolls and the net costs for road provision (capacity costs, plus or minus a lump sum payment or subsidy (if any)). Hence, we neglect other costs for the provider such as maintenance and costs involved with toll collection. A road project is interesting to private firms when a stream of revenues is sufficient to meet their costs and allows them a minimum profit. The costs depend on the size of the project (the capacity of the road), while the revenue depends on the combination of the toll charge and traffic demand for the new road. In our analysis of various auctions we include at some stage the possibility for private firms to ask for a certain amount of subsidy (sub in the model) from the government, that may be necessary to offer a profitable bid. The capacity costs are assumed to be proportional to capacity of the road $\left(c a p_{i}\right)$ with a fixed price per capacity unit $\left(p_{c a p} \text {, equal for both routes }\right)^{3}$;

$$
\pi_{T}=t_{T}^{*} N_{T}-\operatorname{cap}_{T} * p_{c a p}+s u b
$$

Total welfare (W) is now equal to the 'variable' social surplus (the benefits $B$ as given by the relevant area under the demand curve, minus total user costs) minus the total capacity costs:

$$
W=B-N_{U}^{*} c_{U}-N_{T}^{*} c_{T}-\left(\operatorname{cap}_{U}+\operatorname{cap}_{T}\right) * p_{c a p}
$$

All parameters are non-negative, and we will only consider regular networks, where both routes are at least marginally used.

The equilibrium conditions are:

$$
D=p_{U} \text { and } D=p_{T}
$$

and (for all auctions that we will consider):

$$
\pi_{T}=0
$$

\footnotetext{
${ }^{3}$ Note that the average cost function implied by (2) and (3) and the constancy of the unit price for capacity implies that our road network qualifies for the application of the Mohring-Harwitz (1962) result on exact self-financing of optimally designed and priced roads (see also below).
} 


\subsection{Numerical Example}

For the 'base case' of our numerical model, it is assumed that the private road is not yet available, and the following parameter values were chosen: $a=0.1 ; d=140 ; k_{U}=k_{T}=20 ; \beta=$ $20 ; p_{c a p}=2 ; \operatorname{cap}_{U}=1000 ;$ and $c a p_{T}=0$. The base case equilibrium leads to a reasonable demand elasticity of -0.4 , at an equilibrium use of 1000 and equilibrium travel costs that are twice the 'free-flow' level (a table with detailed results is provided in Annex 2). These parameter values were otherwise not motivated by any desire to represent a realistic situation. Before turning to the auctions, we will first discuss a few benchmark situations. The table in Annex 2 gives detailed numerical results, whereas Annex 3 describes the Lagrangian objective functions that have been solved to find these results.

\section{First-best}

The first-best social optimum (maximum welfare) in this network involves an optimization of both the capacity of route $\mathrm{T}$ and both tolls (first-best pricing requires pricing of the whole network). The optimal road price is then equal to 6.32, with marginal private cost of 26.32 and marginal social cost amounting to 32.64 (see Annex 2). The total capacity of both roads together is 3.4 times as high as the initial capacity. This is of course rather extreme. It is a direct consequence of the level of $p_{\text {cap }}$ that we have chosen, relative to the other parameters, and could therefore easily have been avoided. We have however chosen this parametrization so as to create sufficient disparity between the initial equilibrium and the optimum, so that relative differences between various policy options can easily be observed. ${ }^{4}$ Moreover, Figure 4 below shows the results of a sensitivity analysis with respect to $p_{\text {cap }}$. The zero profit result for the provision of road T confirms the so-called Mohring and Harwitz (1962) result of optimal investment. The revenues from an optimal toll will just cover the costs of the facility provider as long as there are no economies or diseconomies of scale in facility capacity and the facility provider is investing optimally.

\section{Second-best}

For the evaluation of the various auctions to be considered, it is useful to know the (welfare) properties of the second-best solution, with only one route tolled and its capacity optimized. Optimal welfare under these conditions (second-best optimum) appears to be only a fraction lower than the first-best optimum $(\omega=0.98)^{5}$. The toll is equal to 0.57 , significantly lower than the first-best toll. However, it is unlikely that private firms will voluntarily offer a road with these specifications, because profits are negative. This means that if the government succeeds in designing an auction that duplicates the second-best outcome, it will have to allow for a subsidy to be given to the private operator.

\footnotetext{
${ }^{4}$ Note also that the sensitivity analysis with respect to the initial capacity, displayed in Figure 2 below, shows that with initial capacities exceeding 1700, auctions that do not allow for a lump-sum subsidy to the bidders would become irrelevant from the perspective of social welfare, as these would no longer be capable of generating any social benefits.

${ }^{5}$ This indicator $\omega$ is defined as the difference between welfare in the situation under study and base case welfare divided by the difference between first best welfare and base case welfare.
} 
Second-best under zero profit constraint

The second-best solution under the zero profit constraint leads to a considerable lower welfare level $(\omega=0.79)$. It is in fact no surprise that the toll level in this situation equals the first-best tolls. In the long run, marginal and average capacity costs per user for route $\mathrm{T}$ are constant. Because we are looking for the second-best optimal situation for this new road, given that no profit or losses should be generated, the ratio of $N_{T}$ divided by the capacity costs of road T is independent of the use of this road, and hence the optimal variable costs will be constant. This means that the average total costs for route $\mathrm{T}$ will be minimized. The optimal charge is now again equal to the average capacity cost per road user, which is 6.32 . Total revenues from the toll charge equal the total capacity costs, as demanded by the zero profit constraint.

\section{Profit maximization}

Without governmental intervention, private ownership of the road will lead to profit maximization. Note that we only consider non-discriminatory fees, the operator is only allowed to set just one toll for all users. The results show that the capacity of the road provided by the private firm will be rather small (compared with the previous optima) and the toll will be equal to 10 . The index of relative welfare improvement $\omega$ is equal to $0.47^{6}$.

\subsection{Auction rules for governments}

We will now consider possible rules that a government may use in an attempt to organize the auction such that a desired outcome is achieved. The scenarios presented in the previous subsection are interesting benchmarks to identify relative efficiency effects, and to determine the performance of the auction rules. Four different auctions are considered, each with a different objective rule ("indicator"). A fifth possible rule will be dismissed shortly. These rules are identified based on plausible aims that the government might have in such a setting. Note that the assumptions we have described in Section 3.2 apply here. Hence, we assume that there is competitive bidding and that there will be zero profits for the winning firm.

\footnotetext{
${ }^{6}$ A remarkable aspect of our model is that the profit maximizing fee turns out to be independent (and equal to 10 in this numerical example) of the road capacity chosen. This is most likely a peculiarity of our linear set-up (although we have not explored this issue any further).
} 


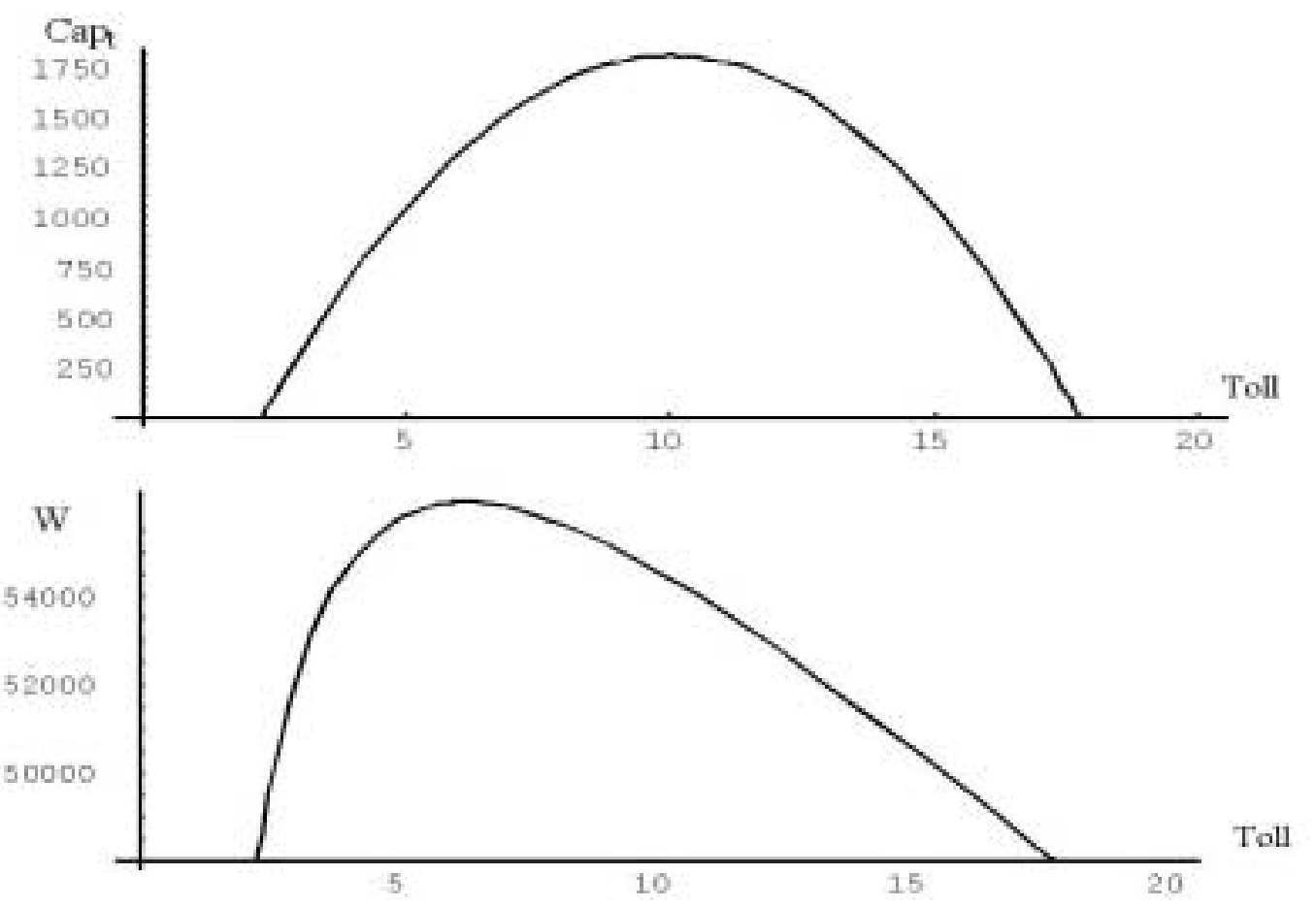

Figure 1: Combination of toll and capacity under zero profit condition (upper panel), and combination of toll and welfare levels under zero profit condition (lower panel)

We first identify combinations of toll and capacity that lead to zero profit for the bidder, when no subsidization is allowed for. The upper panel in Figure 1 shows those combinations between toll and capacity of the new route that lead to zero profit. The figure thus maps out the potential outcomes of an auction in which no lump sum subsidy or payment is foreseen as part of the auction. The lower panel in Figure 1 shows the resulting combinations of welfare and toll (with capacity chosen according to the upper panel). The optimal toll among these is 6.32 (which is the second-best zero profit result).

This figure immediately shows that a fifth possible auction, with the rule to minimize the toll to be charged, is not of interest. The lowest possible toll under a zero-profit condition occurs at a zero capacity, so no practically meaningful bids with positive capacity can be expected from this auction.

\subsubsection{Auction 1: Minimize generalized price, including toll, on route $T$}

A first indicator that the government might use would be to ask bidding firms to minimise generalized travel costs including the toll on the new lane (minimize $c_{T}+t_{T}$ ). Because the value of time is common knowledge, in practice this would for instance mean that the bidders mention the toll they will charge, and the average speed they promise to offer - which is easily converted into travel costs. When bids are evaluated on this criterion, firms have of course the incentive to reduce the toll as well as the travel costs. They also face an incentive to minimize capital costs (per user), as this allows charging a relatively low toll - while preventing losses from operation. The simulation results suggest that the lowest generalized travel cost (including toll) is reached at the same toll where welfare is maximized in a second best situation under zero profit. This occurs, because the firm will minimize its (capacity) costs and due to the indicator also the 
generalized price. Consequently, the average total costs for route $\mathrm{T}$ are minimized and therefore the same result as with 'second-best zero profit' will prevail. This means that the relative welfare improvement indicator is equal for both situations $(\omega=0.79)$, but still substantially below the second-best situation $(\omega=0.98)$; see also Figure 2 . This result suggests that a minimum travel costs indicator may lead to considerable welfare improvement compared to the current situation, but also to an unrestricted monopoly $(\omega=0.47)$.

\subsubsection{Auction 2: Maximize capacity of route $T$}

A second possibility is that the government selects the bid with the largest capacity (e.g. motivated by the hope to minimize congestion). This indicator leads to an upward pressure on the capacity costs of the bidding firm, but does not directly affect the generalized travel costs (only indirectly by increased capacity). The private firm will search for a bid with the largest capacity of route $\mathrm{T}$, but still without making losses. Figure 1 shows the winning zero profit level: a toll of 10 with a capacity of 1800 . The higher toll and larger capacity lead to a smaller welfare gain. The index of relative welfare improvement is about 0.64 , which is, as expected, lower than the previous auction (see also Figure 2). Hence, this criterion is not recommended when regulators aim for maximum welfare. The results show that the larger capacity is not accompanied by larger usage, due to the higher toll. This auction would therefore not necessarily become relatively less attractive when environmental costs from road use were also considered, as one might have anticipated for an auction that maximizes road capacity.

\subsubsection{Auction 3: Minimize subsidy}

For the next two auctions we introduce the possibility of lump-sum payments from, or subsidies to the private operator. Recall that the second-best outcome would require a subsidy. As a first variant, we consider what might be called a 'traditional' auction, namely one in which the winning bid is the one that requires the lowest subsidy, or -equivalently- promises the largest payment for the right to build and operate the road (when $s u b$ is negative). The amount of subsidy (which has been set at zero in the previous auctions) is included in the profit function (4). It appears that the minimum level of the subsidy (negative, indicating that firms are willing to pay) is reached at a capacity of 697 , and a toll of 10 . The result is equal to the outcome of unconstrained profit maximisation, as may be expected. It indicates that firms will set the price and capacity in such a way that they can pay the government the highest price (all profits) without making losses. The auction forces the firms to choose a (pre-subsidy) profit maximizing toll and capacity, which are known to lead to potentially considerable welfare losses. This is therefore not a very attractive option from the efficiency perspective $(\omega=0.47)$.

\subsubsection{Auction 4: Minimize travel costs and subsidy divided by total traffic demand}

The fourth rule that we consider combines the subsidy requested and the generalized travel costs (including a toll) on the new road. The aim reflects the desires for low travel costs and a small subsidy. The indicator is defined as $c_{T}+t_{T}+s u b /\left(N_{T}+N_{U}\right)$. The resulting welfare level is very near the second best outcome and the index of relative welfare improvement is nearly equal to the second-best solution. However, a subsidy is required to approach the second-best optimum, since this second-best optimum cannot be realised without losses. This auction rule outperforms all other indicators in terms of welfare gains. This can be explained by the fact that it forces firms to minimize total costs (travel and capacity costs, as in auction 1), but while requesting a 
small subsidy. This subsidy is in fact used to increase capacity of route $\mathrm{T}$ while keeping toll levels low, all leading to increased welfare levels compared to no-subsidy auctions.

Note that the indicator asks the firm to consider $\mathrm{sub} /\left(N_{T}+N_{U}\right)$ for minimization, not the subsidy per user of the pay-lane $\left(s u b / N_{T}\right)$. The latter indicator was also tested, but appeared to provide perverse incentives in pushing the toll to very low, even negative, levels. The reason is that a lowering of the toll increases $N_{T}$ and therefore helps in lowering $s u b / N_{T}$, but does so at the expense of attracting too many users from route $\mathrm{U}$. By including $N_{U}$ in the denominator of the third term in the indicator, this perverse incentive is removed. Figure 2 below will show that as the capacity of route $U$ and hence its equilibrium use approaches zero, the present indicator remains performing well. The declining impact of $N_{U}$ in the indicator is matched by the fact that a low capacity of road $U$ means that the described perverse incentive in terms of inefficient route split also vanishes.

Annex 4 presents the analytical solution for this auction, and demonstrates that the bidders firstorder condition for optimizing capacity coincides with the second-best first-order condition, while the optimal toll in both regimes shows a discrepancy which apparently is of minor importance under the base case parameters.

\subsection{Sensitivity analysis}

The previous results for $\omega$ are of course likely to change with parameter values chosen. In order to consider the robustness of our results, we have analyzed three types of effects. First, we will look at the effect of changing the capacity of the untolled route on $\omega$. Next, the impact of demand elasticity on $\omega$ for the various auctions will be investigated. And thirdly, we consider changes in $p_{\text {cap }}$. Finally, we will briefly discuss the possible effects of changing some of our basic underlying assumptions.

\section{Varying the capacity of the untolled lane}

Figure 2 shows the results of relative welfare improvements for the various auctions when changing the capacity of the untolled lane (recall that all previous results concern a capacity of the untolled lane of 1000). An $\omega$ of 1 is the first-best result, and both second-best situations approach the first-best optimum when the capacity of the existing road decreases and the amount of unpriced capacity decreases.

It appears that the well-performing criterion of the minimization of travel costs (auction 1: A1) maintains a high $\omega$, equal to the second best situation under a zero profit constraint, for changing capacities of the untolled lane. When this capacity approaches zero, auction 1 approaches maximum efficiency, since - due to the Mohring-Harwitz result - no subsidies are required when initial capacity is zero and the new road is designed and priced optimally. Auction rule 4 (A4 in figure 2, minimizing travel costs and subsidy divided by total traffic demand) also remains nearly equal to the second-best situation without zero profit constraint for all capacities shown. It appears that results depend heavily on the capacity of the untolled lane. The figure shows that when congestion is more likely to occur (when decreasing the capacity of the untolled lane), the performance of most indicators improves. An exception is auction rule 2 . This reflects that the discrepancy between optimal capacity and the maximum capacity that can be supplied against zero profits increases as the capacity of the untolled road decreases. This accompanied by an increasing difference between the toll from the auction and the second-best optimal toll, inducing further distortions from this auction 2. On the other hand, when the capacity of the initial lane is 
sufficiently large, it becomes more difficult to achieve welfare gains at all from adding a paylane, because the second-best constraint of unpriced capacity becomes relatively more important.

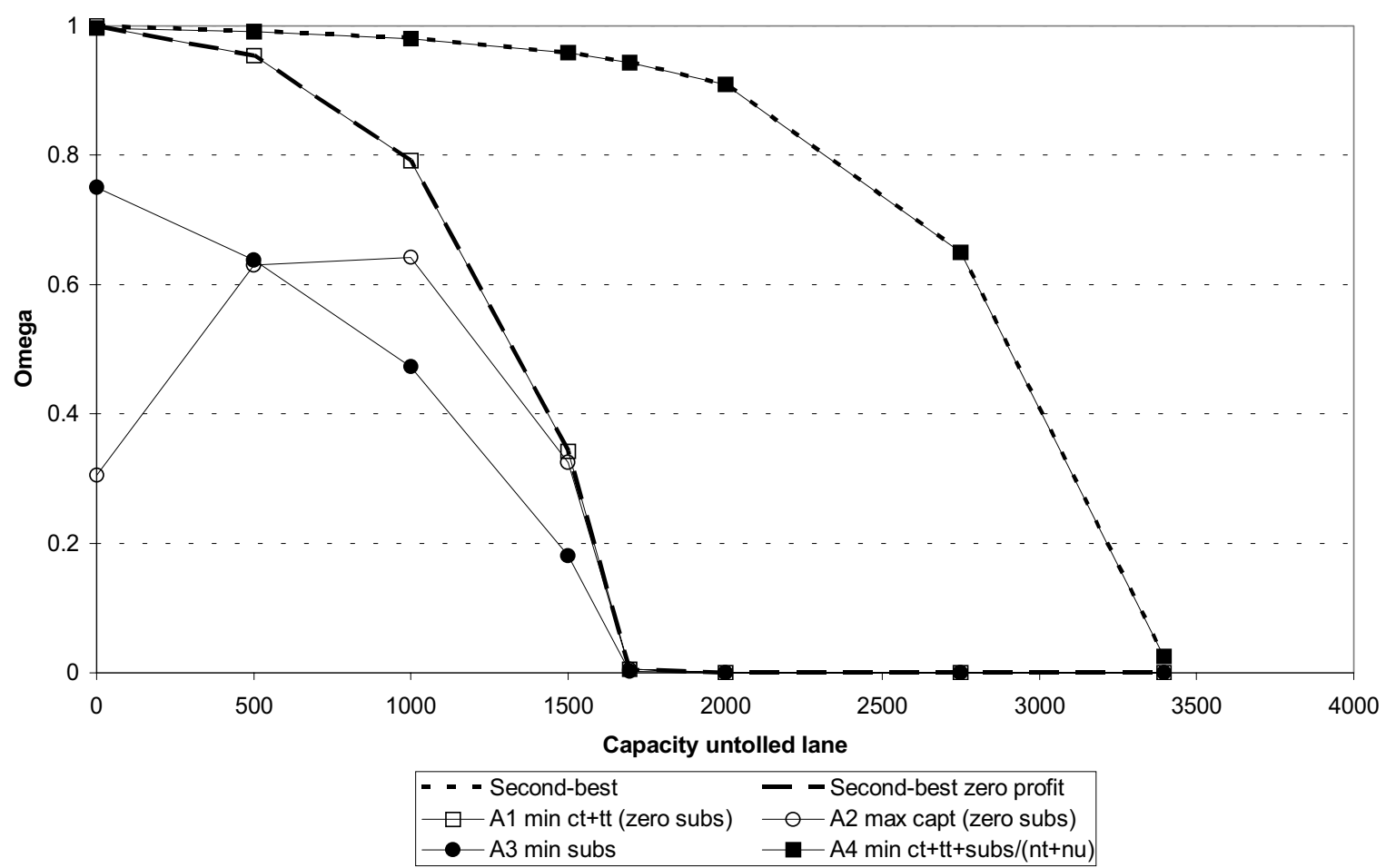

Figure 2: The index of relative welfare improvement for the auctions with various capacities of the untolled route

Varying demand elasticity

Figure 3 shows the results in terms of $\omega$ when changing the equilibrium demand elasticity (by simultaneously changing the parameter values of $a$ and $d$ such that the same base equilibrium is obtained for every elasticity). It indicates that the results are rather robust for different demand elasticities; the prevailing demand structure is apparently not a crucial factor. This may appear surprising at first sight, especially because prior studies of profit maximizing tolling on a paylane have emphasized the importance of demand elasticity upon its relative efficiency (e.g. Verhoef, Nijkamp and Rietveld, 1996; Verhoef and Small, 2003). The reason why this is not the case in the present set-up is that not only the toll but also the capacity of the priced road is adjusted in response to changes in demand elasticity. As a result, $N_{U}$ and $C_{U}$ remain constant for nearly each scenario along the demand elasticities shown in Figure 3, with the exception for second-best and Auction 4 (where small changes are observed). The same holds for $c_{T}$ (constant for all scenarios) and $t_{T}$ (relatively large changes in a relatively small absolute toll value occur only in - again - second-best and Auction 4). The demand elasticity therefore only determines the 'size' of the new market (on road T), expressed in $\operatorname{cap}_{T}$ and $N_{T}$, but leaves the relative efficiency effects of the various scenarios largely unaffected. 


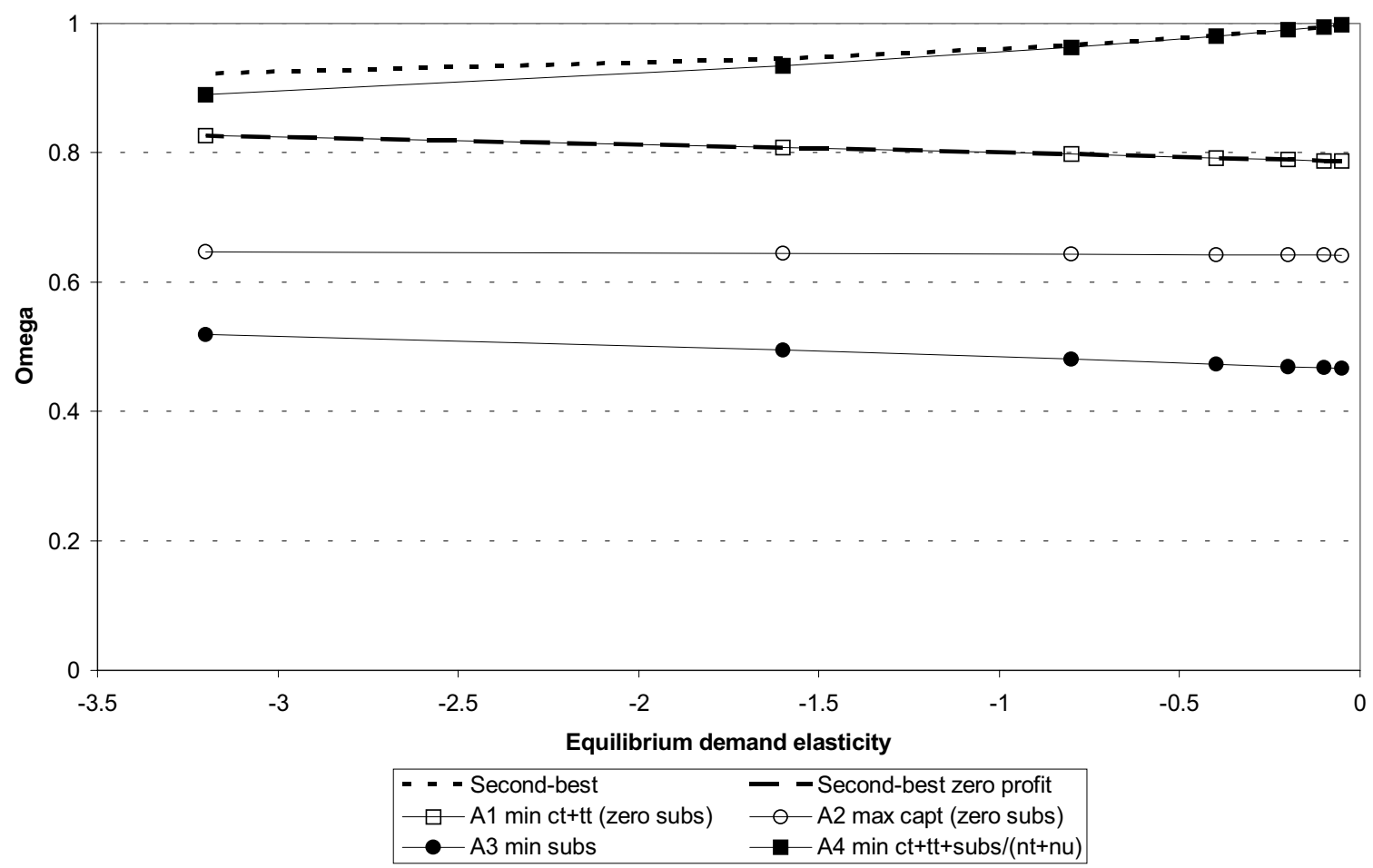

Figure 3: The index of relative welfare improvement for the auctions with various demand elasticities

Varying the price of road capacity

Figure 4 shows what happens with $\omega$ for the various auctions when changing the unit price of road capacity $\left(p_{c a p}\right)$. Note that the patterns are similar to those of Figure 2. Increasing the price of capacity leads to considerable lower welfare gains for most auctions, except for auction 4 (over the range shown). Note that the performance of auctions 1 and 4 again remains (nearly) equal to their second-best counterparts. When it becomes cheaper to construct a road, it is more likely that capacities will increase (attracting more road users) and hence tolling becomes more efficient for all cases. The results suggest that auction 4 may be particularly useful to policy makers when considering the construction of a new road in (congested) urban areas by a private consortium. Higher land prices may make it more expensive to build a new road. The relevant part of Figure 4 to consider would be the right-hand side, where the relative, where the relative advantage of auction 4 over the other auctions increases rapidly. 


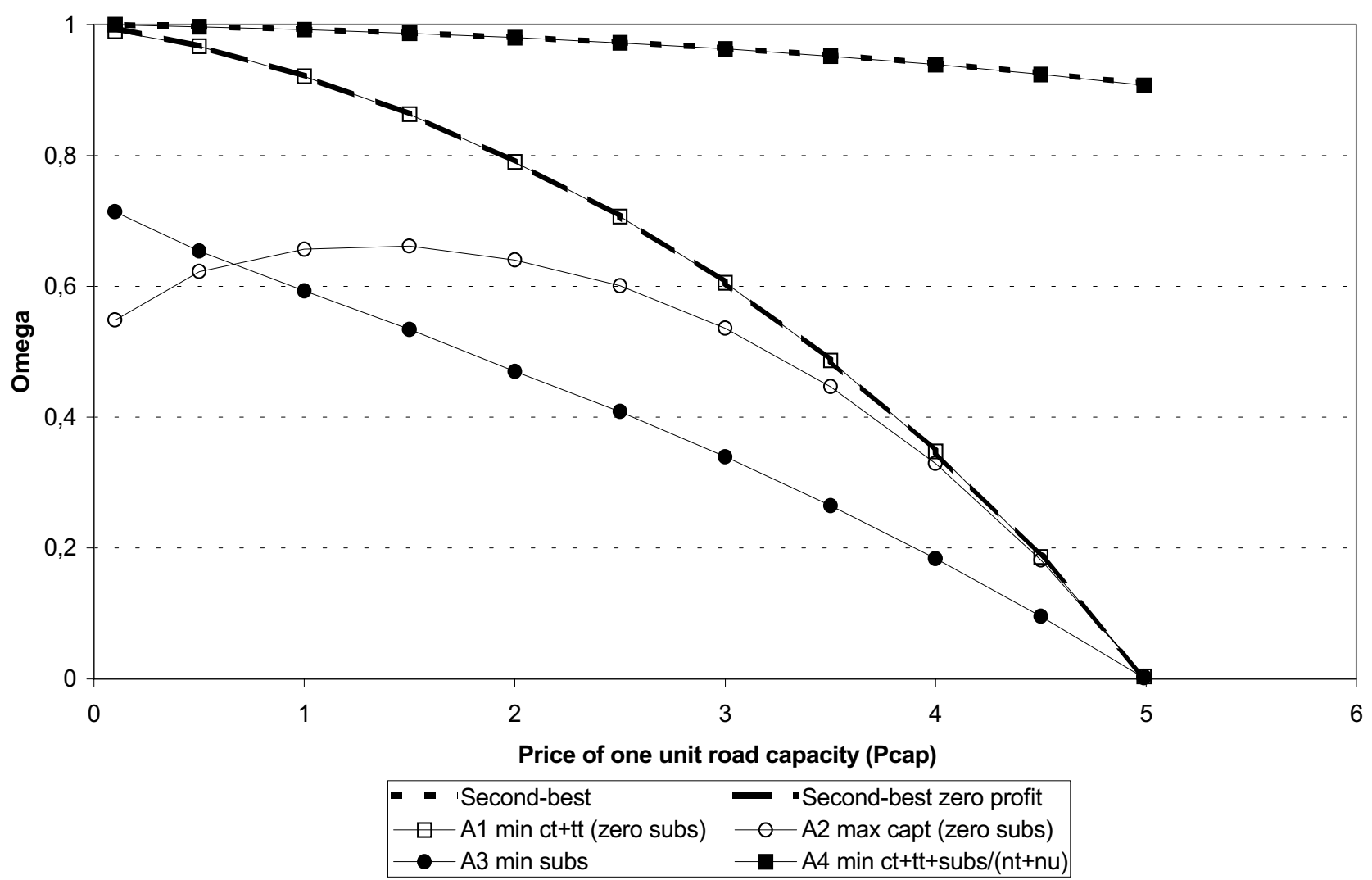

Figure 4: The index of relative welfare improvement for the auctions with various prices of road capacity $^{7}$

Limitations of the analysis

Of course, the simulation results we present only hold under specific conditions. We assume, for instance, that we live in a static world, but do not discuss what will happen when the demand function would change over time. Depending on how rational bidders are when making their bids and on whether or not such issues can be incorporated in auctions, the results may of course change. Another issue is that private firms might be tempted not to obey what was promised in the bids. Obviously, a contract between firm and government should clearly specify the details of the winning bid (toll and capacity), and penalties should guarantee that companies do make serious offers. We have also assumed that all firms are equal, and that the price of one unit of capacity is given. It remains to be seen what will happen when only a few firms co-operate near the efficiency frontier. Likewise, a fully competitive bidding process was assumed, without collusion between firms. But firms may decide to make mutual arrangements about offers in terms of price and capacity. Governments may then face unattractive offers. One possibility to circumvent the resulting potential problems at least to some extent is to keep the option open to build the road publicly. And the number of competing firms can, particularly for a smaller country, be increased when also inviting foreign bidders.

\footnotetext{
${ }^{7}$ High levels of capacity prices (more than 5) imply no meaningful results for auctions 1,2 and 3, as they lead to zero capacities.
} 
Despite the simplifying assumptions underlying our model, the results may remain relevant to governments organizing an auction. If anything, the results show that the choice of the 'indicator' is - as expected - an important determinant for the results of the auctions. Our results suggest that such an indicator should include travel times guaranteed $\left(c_{T}\right)$, toll levels to be charged $\left(t_{T}\right)$, and preferably also the lump-sum subsidy required $(\mathrm{sub})$. Allowing for such a subsidy improves social welfare when this subsidy is relevant, but does not seem to diminish the auction's efficiency when the second-best optimal level of the subsidy becomes small (e.g. when initial capacity becomes small in Figure 2).

\section{Conclusions}

Regulation of private firms operating road infrastructure can take several forms. In this paper we considered regulation by means of an auction organized by the government. We studied private involvement in road provision in a competitive bidding setting and analysed the effects of imposing various auction rules ("indicators") by the government. We considered a simple network with one origin and one destination connected by two parallel routes, of which one is to be constructed and operated by a private firm. This is practically relevant since expansion of existing road capacity is often that type of road building considered nowadays. Using a simulation model, we investigated the effects of various indicators on the outcomes of the auction. Different criteria may lead to rather different road capacities and tolls bid by private companies.

First, we analysed the cases of first-best pricing, second-best pricing, second-best pricing with zero profits and maximum profits. Second-best pricing leads to a relative small welfare loss, while profits are negative. The "second-best zero profit" toll level is equal to the first-best toll, because average capacity costs per road user on this new route will be the same in both situations (long-run costs will be minimized).

We have analysed the welfare consequences of four different, but plausible, rules that may be used by the government to organize the bidding process. It appeared that the criterion of the minimization of generalized price on the tolled road scores equal to the second best situation under a zero profit constraint. An indicator that rewards increases in capacity does not lead to very promising results in terms of welfare. Minimizing the requested subsidy only results in the same outcome as unconstrained profit maximization, and is therefore not very attractive. As expected, firms will offer the maximum profits to the government. Minimizing generalized travel costs including the toll on the new road, plus the subsidy divided by total traffic demand outperforms the simpler generalized price (again including toll) criterion in terms of relative efficiency. This can be explained by the fact that this winning rule not only minimizes travel costs but also allows a subsidy, while the second-best optimum would indeed imply losses for the operator. The subsidy is used to increase capacity and to lower the toll, leading to larger welfare gains.

Finally, we have looked at the sensitivity of the results by changing the capacity of the untolled lane, the equilibrium demand elasticity and the unit cost of capacity. It appears that results change significantly when changing the capacity of the untolled lane. The performance of most indicators generally improves when a smaller portion of total capacity remains untolled, and when congestion is more likely to occur (i.e., with a decreasing capacity of the untolled lane). On the other hand, when the capacity of the present lane is sufficiently high, it is very hard to achieve welfare gains. Similar patterns were observed for, respectively, lower versus higher costs 
of capacity. The results are rather robust for different demand elasticities. This was mainly because capacities are adjusted in the face of changes in demand elasticity, which affects the scale of the new road for all scenarios considered, but not their relative performance.

\section{References}

De Palma, A. and R. Lindsey, 2000, Private Toll Roads: Competition under Various Ownership Regimes, The Annals of Regional Science, 34, pp. 13-35.

Edelson, N.E., 1971, Congestion tolls under monopoly, American Economic Review, 61 (5), pp. 872-882.

Fisher, G. and S. Babbar, 1996, Private Financing of Toll Roads, RMC Discussion paper, Worldbank, Washington D.C.

Gomez - Ibanez, J.A. and J.R. Meyer, 1993, Going Private: The International Experience with Transport Privatization, The Brookings Institution, Washington D.C.

ITS Leeds and partners, 1999, Deliverable 4 of Project FATIMA, Leeds

Levinson, D., R.C. Garcia and K. Carlson, 2003, Public Private Partnerships, paper presented at the STELLA (focus group 5) meeting in Santa Barbara, pp. 40.

Knight, F.H., 1924, Some Fallacies in the Interpretation of Social Costs, Quarterly Journal of Economics, 38, pp. 582-606.

Lévy-Lambert, H., 1968, Tarification des services à qualité variable: application aux péages de circulation, Econometrica, 36 (3-4), pp. 564-574.

Liu, N.L. and J.F. McDonald, 1998, Efficient congestion tolls in the presence of unpriced congestion: a peak and off-peak simulation model, Journal of Urban Economics, 44, pp. 352-366.

Marchand, M., 1968, A note on optimal tolls in an imperfect environment, Econometrica, 36 (34), pp. 575-581.

Mills, D.E., 1981, Ownership arrangements and congestion-prone facilities, American Economic Review, Papers and Proceedings, 71 (3), pp. 493-502.

Mohring, H and Harwitz, M., 1962, Highway Benefits: An Analytical Framework, in Northwestern University Press, Evanston.

NERA, COWI, and BPM, 1998, Infrafin, Final Report for Publication, project funded by the EC under the transport RTD programme of the 4th framework, London. 
Rienstra, S.A. and P. Nijkamp, 1997, Lessons from Private Financing of Transport Infrastructure, Revue Economique, 48 2, pp. 231-245.

Small, K.A., 1999, Economies of scale and self-financing rules with non-competitive factor markets, Journal of Public Economics, 74, pp. 431-450.

Small, K.A., C. Winston, and C.A. Evans, 1989, Road Work, The Brookings Institutional, Washington D.C.

Tsai, J-F, and C-P Chu, 2003, The Analysis of Regulation on Private Highway Investment under a Build-Operate-Transfer Scheme, Transportation, 30, pp. 221-243.

Ubbels, B., 2002, The Economics of Transport Pricing, In: Colloquium Vervoersplanologisch Speurwerk: De kunst van het verleiden?, Delft, CVS, pp. 201-219

Vickerman, R., 2002, Public and Private Initiatives in Infrastructure Provision, Paper presented at the Stella Workshop in Brussels (26-27 April, 2002)

Verhoef, E.T., P. Nijkamp and P. Rietveld, 1996, Second-best congestion pricing: The case of an untolled alternative, Journal of Urban Economics, 40(3), pp. 279-302.

Verhoef, E.T. and K.A. Small, 2003, Product differentiation on roads: constrained congestion pricing with heterogeneous users, Journal of Transport Economics and Policy, forthcoming.

Yang, H. and Q. Meng, 2000, Highway pricing and capacity choice in a road network under a build-operate-transfer scheme, Transportation Research Part A, Vol. 34, pp. 207-222

Wardrop, J., 1952, Some Theoretical Aspects of Road Traffic Research, Proceedings of the Institute of civil Engineers, 1, pp. 325-378. 


\section{Annex 1: List of Symbols}

$\begin{array}{ll}N & \text { Total number of road users } \\ N_{T} & \text { Number of road users on the tolled route } \\ N_{U} & \text { Number of road users on the untolled route } \\ \mathrm{D}(\mathrm{N}) & \text { Inverse demand function } \\ \mathrm{c}_{\mathrm{T}} & \text { Average social (=marginal private) cost on the tolled route } \\ \mathrm{c}_{\mathrm{U}} & \text { Average social (=marginal private) cost on the untolled route } \\ \text { cap }_{\mathrm{T}} & \text { Capacity of the tolled route } \\ \text { cap }_{U} & \text { Capacity of the untolled route } \\ \mathrm{W} & \text { Welfare } \\ \mathrm{B} & \text { Benefits } \\ \pi_{\mathrm{t}} & \text { Profit for the firm that provides road T } \\ \mathrm{p}_{\mathrm{i}} & \text { Price for route i (including cost and toll) } \\ \mathrm{t}_{\mathrm{T}} & \text { Toll } \\ \mathrm{p}_{\mathrm{cap}} & \text { Price of one unit road capacity } \\ \mathrm{k}_{\mathrm{i}} & \text { Average free flow user cost on route } \mathrm{i} \\ \mathrm{b}_{\mathrm{i}} & \text { Slope of the average cost function on route } \mathrm{i} \text { (dependent on capacity) } \\ \beta & \text { Constant } \\ \omega & \text { Index of relative welfare improvement } \\ \mathrm{a} & \text { Slope of the demand curve (negative) } \\ \mathrm{d} & \text { Intersection of the demand curve with the vertical axis } \\ \text { sub } & \text { amount of subsidy included in the offer of the private firm }\end{array}$




\section{Annex 2: Numerical Results}

The following table presents the numerical results for various scenarios. The first column is an equilibrium situation, the other cases are the welfare optimal outcomes.

\begin{tabular}{|l|c|c|c|c|c|c|c|c|c|c|}
\hline Scenario & $\mathbf{N}_{\mathbf{T}}$ & $\mathbf{N}_{\mathbf{U}}$ & $\mathbf{c a p}_{\mathbf{T}}$ & $\mathbf{c a p}_{\mathbf{U}}$ & $\mathbf{W}$ & $\boldsymbol{\pi}_{\mathbf{T}}$ & $\mathbf{t}_{\mathbf{T}}$ & $\mathbf{t}_{\mathbf{U}}$ & $\mathbf{s u b}$ & $\boldsymbol{\omega}$ \\
\hline Base equilibrium & 0 & 1000 & 0 & 1000 & 48000 & 0 & 0 & 0 & - & - \\
\hline First-best & 757 & 316 & 2395 & 1000 & 57621 & 0 & 6.32 & 6.32 & - & 1 \\
\hline Second-best & 786 & 345 & 2486 & 1000 & 57439 & -4519 & 0.57 & 0 & - & 0.98 \\
\hline $\begin{array}{l}\text { Second-best (zero } \\
\text { profit) }\end{array}$ & 441 & 632 & 1395 & 1000 & 55621 & 0 & 6.32 & 0 & - & 0.79 \\
\hline $\begin{array}{l}\text { Profit } \\
\text { maximization }\end{array}$ & 221 & 816 & 697 & 1000 & 52553 & 811 & 10 & 0 & - & 0.47 \\
\hline $\begin{array}{l}\text { Auction 1 } \\
\text { Minimize generalized } \\
\text { price (including toll) on } \\
\text { route T }\end{array}$ & 441 & 632 & 1395 & 1000 & 55621 & 0 & 6.32 & 0 & 0 & 0.79 \\
\hline $\begin{array}{l}\text { Auction 2 } \\
\text { Maximize capacity of } \\
\text { route T }\end{array}$ & 360 & 700 & 1800 & 1000 & 54180 & 0 & 10 & 0 & 0 & 0.64 \\
\hline $\begin{array}{l}\text { Auction 3 } \\
\text { Minimize subsidy }\end{array}$ & 221 & 816 & 697 & 1000 & 52553 & 0 & 10 & 0 & -811 & 0.47 \\
\hline $\begin{array}{l}\text { Auction 4 } \\
\text { Minimize generalized } \\
\text { price (including toll) on } \\
\text { route T including } \\
\text { subsidy divided by } \\
\text { total travel demand }\end{array}$ & 810 & 325 & 2561 & 1000 & 57430 & 0 & 0.18 & 0 & 4980 & 0.98 \\
\hline
\end{tabular}




\section{Annex 3: Description of the Lagrangian objective functions}

The relevant optima (the numerical results can be found in Annex 2) have been found by solving the following Lagrangian functions for the benchmark situations and the auctions under study. These functions were differentiated with respect to the mentioned choice variables to find the first-order conditions. It would take too far to present all these necessary first-order conditions, so we have limited ourselves to presenting the Lagrangians of our problems. The Lagrange multipliers $\lambda_{T}$ and $\lambda_{U}$ refer to the equilibrium constraints that marginal benefits equal prices on both roads. The Langrange multiplier on the zero profit constraint is $\lambda_{\pi}$.

\section{First-best optimum}

$L=\int_{0}^{N} D(n) d n-N_{T} * c_{T}-N_{U} * c_{U}-\left(\operatorname{cap}_{U}+\operatorname{cap}_{T}\right) * p_{c a p}+\lambda_{T}\left(D(N)-p_{T}\right)+\lambda_{U}\left(D(N)-p_{U}\right)$

This equation was solved for $N_{T}, N_{U}, \operatorname{cap}_{T}, t_{T}, t_{U}, \lambda_{T}$ and $\lambda_{U}$.

\section{Second-best optimum}

$L=\int_{0}^{N} D(n) d n-N_{T} * c_{T}-N_{U} * c_{U}-\left(\operatorname{cap}_{U}+\operatorname{cap}_{T}\right) * p_{c a p}+\lambda_{T}\left(D(N)-p_{T}\right)+\lambda_{U}\left(D(N)-p_{U}\right)$

This equation was solved for $N_{T}, N_{U}, \operatorname{cap}_{T}, t_{T}, \lambda_{T}$ and $\lambda_{U}$, with $t_{U}=0$.

\section{Second-best optimum with zero profit condition}

$$
\begin{aligned}
& L=\int_{0}^{N} D(n) d n-N_{T} * c_{T}-N_{U} * c_{U}-\left(\operatorname{cap}_{U}+\operatorname{cap}_{T}\right) * p_{c a p}+\lambda_{T}\left(D(N)-p_{T}\right)+\lambda_{U}\left(D(N)-p_{U}\right) \\
& +\lambda_{\pi}\left(t_{T} * N_{T}-\operatorname{cap}_{T} * p_{c a p}+s u b\right)
\end{aligned}
$$

This equation was solved for $N_{T}, N_{U}, \operatorname{cap}_{T}, t_{T}, \lambda_{T}, \lambda_{\pi}$ and $\lambda_{U}$, with $t_{U}=0$.

\section{Profit maximization}

$L=t_{T} * N_{T}-\operatorname{cap}_{T} * p_{\text {cap }}+s u b+\lambda_{T}\left(D(N)-p_{T}\right)+\lambda_{U}\left(D(N)-p_{U}\right)$

This equation was solved for $N_{T}, N_{U}, \operatorname{cap}_{T}, t_{T}, \lambda_{T}$ and $\lambda_{U}$, with $t_{U}=0$.

\section{Auction 1: Minimize $p_{T}$ (zero profits and no subsidy)}

$L=p_{T}+\lambda_{T}\left(D(N)-p_{T}\right)+\lambda_{U}\left(D(N)-p_{U}\right)+\lambda_{\pi}\left(t_{T} * N_{T}-c a p_{T} * p_{c a p}+s u b\right)$

This equation was solved for $N_{T}, N_{U}, \operatorname{cap}_{T}, t_{T}, \lambda_{T}, \lambda_{\pi}$ and $\lambda_{U}$, with $t_{U}=0$.

Auction 2: Maximize $\operatorname{cap}_{T}$ (zero profits and no subsidy)

$L=\operatorname{cap}_{T}+\lambda_{T}\left(D(N)-p_{T}\right)+\lambda_{U}\left(D(N)-p_{U}\right)+\lambda_{\pi}\left(t_{T} * N_{T}-\operatorname{cap}_{T} * p_{\text {cap }}+s u b\right)$

This equation was solved for $N_{T}, N_{U}, \operatorname{cap}_{T}, t_{T}, \lambda_{T}, \lambda_{\pi}$ and $\lambda_{U}$, with $t_{U}=0$.

\section{Auction 3: Minimize $s u b$ (zero profits with subsidy)}


$L=s u b+\lambda_{T}\left(D(N)-p_{T}\right)+\lambda_{U}\left(D(N)-p_{U}\right)+\lambda_{\pi}\left(t_{T} * N_{T}-c a p_{T} * p_{c a p}+s u b\right)$

This equation was solved for $N_{T}, N_{U}, \operatorname{cap}_{T}, t_{T}, \lambda_{T}, \lambda_{U}, \lambda_{\pi}$ and $s u b$, with $t_{U}=0$.

Auction 4: Minimize $p_{T}+s u b /\left(N_{T}+N_{U}\right)$ (zero profits with subsidy)

$L=p_{T}+\operatorname{sub} /\left(N_{T}+N_{U}\right)+\lambda_{T}\left(D(N)-p_{T}\right)+\lambda_{U}\left(D(N)-p_{U}\right)+\lambda_{\pi}\left(t_{T} * N_{T}-c a p_{T} * p_{c a p}+s u b\right)$

This equation was solved for $N_{T}, N_{U}, \operatorname{cap}_{T}, t_{T}, \lambda_{T}, \lambda_{U}, \lambda_{\pi}$ and $s u b$, with $t_{U}=0$. 


\section{Annex 4: Derivation of first-order solutions of optimal capacity and optimal toll for the second-best situation and auction 4}

This annex presents the derivation of the expressions for the first-order conditions for optimizing capacity and optimizing toll for both the second-best situation and auction rule 4 (minimize generalized travel costs plus subsidy divided by total traffic demand). It will be shown that the bidders first-order condition for optimizing capacity coincides with the second-best first-order condition, while the optimal toll in both regimes shows a certain discrepancy. We will start with the derivation of the analytical solution for the second-best case. This is followed by the derivation of the optimal toll and the first-order expression of optimal capacity for auction rule 4.

\section{Second-best optimal toll and expression for optimal capacity}

$L=\int_{0}^{N} D(n) d n-N_{T} * c_{T}-N_{U} * c_{U}-\left(\operatorname{cap}_{U}+\operatorname{cap}_{T}\right) * p_{c a p}+\lambda_{T}\left(p_{T}-D(N)\right)+\lambda_{U}\left(p_{U}-D(N)\right)$

$\frac{\partial L}{\partial N_{T}}=D-c_{T}-N_{T} * \frac{\partial c_{T}}{\partial N_{T}}+\lambda_{T}\left(\frac{\partial c_{T}}{\partial N_{T}}-\frac{\partial D}{\partial N_{T}}\right)-\lambda_{U} * \frac{\partial D}{\partial N}=0$

$\frac{\partial L}{\partial N_{U}}=D-c_{U}-N_{U} * \frac{\partial c_{U}}{\partial N_{U}}-\lambda_{T} \frac{\partial D}{\partial N}+\lambda_{U}\left(\frac{\partial c_{U}}{\partial N_{U}}-\frac{\partial D}{\partial N}\right)=0$

$\frac{\partial L}{\partial c a p_{T}}=-N_{T} * \frac{\partial c_{T}}{\partial c a p_{T}}-p_{c a p}+\lambda_{T} * \frac{\partial c_{T}}{\partial c a p_{T}}=0$

$\frac{\partial L}{\partial t_{T}}=\lambda_{T}=0$

$\frac{\partial L}{\partial \lambda_{T}}=c_{T}+t_{T}-D=0$

$\frac{\partial L}{\partial \lambda_{U}}=c_{U}-D=0$

Substituting equation (7) and (5) in (3) yields:

$\lambda_{U}=\frac{N_{U} * \frac{\partial c_{U}}{\partial N_{U}}}{\frac{\partial c_{U}}{\partial N_{U}}-\frac{\partial D}{\partial N}}$

The solution for the optimal second-best toll follows from substituting (8), (6) and (5) in (2): 


$$
t_{T}=N_{T} * \frac{\partial c_{T}}{\partial N_{T}}-N_{U} * \frac{\partial c_{U}}{\partial N_{U}} * \frac{-\frac{\partial D}{\partial N}}{\frac{\partial c_{U}}{\partial N_{U}}-\frac{\partial D}{\partial N}}
$$

This is the standard second-best optimal toll consisting of the first-best toll minus a term that corrects for congestion on the untolled parallel road (see also Verhoef, Nijkamp and Rietveld, 1996).

The second-best first-order condition for optimal capacity is obtained when (5) is substituted in (4):

$$
p_{c a p}=N_{T} *-\frac{\partial c_{T}}{\partial c a p_{T}}
$$

As for first-best capacity choice, capacity should be expanded up to the point where the marginal costs of doing so ( $p_{c a p}$ on the left-hand side of $\left.(10)\right)$ are equal to the marginal benefits (the righthand side).

\section{Auction rule 4: optimal toll and first-order condition for optimal capacity}

$$
L=p_{T}+\frac{s u b}{N_{T}+N_{U}}+\lambda_{T}\left(p_{T}-D(N)\right)+\lambda_{U}\left(p_{U}-D(N)\right)+\lambda_{\pi}\left(t_{T} * N_{T}-c a p_{T} * p_{c a p}+s u b\right)
$$

First we derive:

$$
\begin{aligned}
& \frac{\partial L}{\partial s u b}=\lambda_{\pi}+\frac{1}{N_{T}+N_{U}}=0 \Rightarrow \lambda_{\pi}=\frac{-1}{N_{T}+N_{U}} \\
& \frac{\partial L}{\partial t_{T}}=1+\lambda_{T}+\lambda_{\pi} * N_{T}=0 \Rightarrow \lambda_{T}=-1+\frac{N_{T}}{N_{T}+N_{U}}=\frac{-N_{U}}{N_{T}+N_{U}}
\end{aligned}
$$

and use these expressions directly in what follows.

The first-order conditions for $N_{U}$ and $N_{T}$ are:

$$
\begin{aligned}
& \frac{\partial L}{\partial N_{U}}=-\frac{s u b}{\left(N_{T}+N_{U}\right)^{2}}-\frac{N_{U}}{N_{T}+N_{U}} *-\frac{\partial D}{\partial N_{U}}+\lambda_{U}\left(\frac{\partial c_{U}}{\partial N_{U}}-\frac{\partial D}{\partial N_{U}}\right)=0 \\
& \frac{\partial L}{\partial N_{T}}=\frac{\partial c_{T}}{\partial N_{T}}-\frac{s u b}{\left(N_{T}+N_{U}\right)^{2}}-\frac{N_{U}}{N_{T}+N_{U}} *\left(\frac{\partial c_{T}}{\partial N_{T}}-\frac{\partial D}{\partial N}\right)-\lambda_{U}\left(\frac{\partial D}{\partial N}\right)-\frac{1}{N_{T}+N_{U}} * t_{T}=0
\end{aligned}
$$


Substituting (15) in (14) leaves the following expression for the optimal toll:

$$
t_{T}=N_{T} * \frac{\partial c_{T}}{\partial N_{T}}-\lambda_{U} * \frac{\partial c_{U}}{\partial N_{U}} *\left(N_{T}+N_{U}\right)
$$

Rewriting (14) we find an expression for $\lambda_{U}$. Using this expression in (16) gives the following solution for the optimal toll for auction rule 4 :

$$
t_{T}=N_{T} * \frac{\partial c_{T}}{\partial N_{T}}-N_{U} * \frac{\partial c_{U}}{\partial N_{U}} * \frac{-\frac{\partial D}{\partial N}}{\frac{\partial c_{U}}{\partial N_{U}}-\frac{\partial D}{\partial N}}-\frac{\frac{\partial c_{U}}{\partial N_{U}}}{\frac{\partial c_{U}}{\partial N_{U}}-\frac{\partial D}{\partial N}} * \frac{s u b}{N_{T}+N_{U}}
$$

Note that (17) is an implicit solution for $t_{T}$, since $s u b$ still appears on the right-hand side. Nevertheless, the expression in (17) is insightful as it shows that the toll expression is almost equal to the second-best toll as shown in (9), but differs in an extra term that should be subtracted. For a positive subsidy, the optimal toll for this auction rule will be below the optimal second-best toll, as is also shown in the numerical results. Admittedly simplistic intuition suggests that this last term need not be large (and hence does not lead to large deviations from the optimal second-best toll), because the auction rule asks bidders to also minimize $\frac{s u b}{N_{T}+N_{u}}$.

Finally, the expressions for $\lambda_{T}$ and $\lambda_{\pi}$ in equations (12) and (13) imply:

$$
\begin{aligned}
& \frac{\partial L}{\partial \operatorname{cap}_{T}}=\frac{\partial c_{T}}{\partial \operatorname{cap}_{T}}-\frac{N_{U}}{N_{U}+N_{T}} * \frac{\partial c_{T}}{\partial \operatorname{cap}_{T}}+\frac{p_{\text {cap }}}{N_{T}+N_{U}}=\frac{N_{T}}{N_{T}+N_{U}} * \frac{\partial c_{T}}{\partial c a p_{T}}+\frac{p_{c a p}}{N_{T}+N_{U}}=0 \Rightarrow \\
& p_{\text {cap }}=-N_{T} * \frac{\partial c_{T}}{\partial \operatorname{cap}_{T}}
\end{aligned}
$$

Indeed, this term equals the first-order condition for optimal capacity in the second-best situation (as shown in (10)). 